\title{
Three-Dimensional Reservoir Modeling Using Stochastic Simulation, a Case Study of an East African Oil Field
}

\author{
Margaret Akoth Oloo, Congjiao Xie * \\ Faculty of Earth Resources, China University of Geosciences, Wuhan, China \\ Email: a.maggarett@yahoo.com, *cxie2004@cug.edu.cn
}

How to cite this paper: Oloo, M.A. and Xie, C.J. (2018) Three-Dimensional Reservoir Modeling Using Stochastic Simulation, a Case Study of an East African Oil Field. International Journal of Geosciences, 9, 214-235.

https://doi.org/10.4236/ijg.2018.94014

Received: January 4, 2018

Accepted: April 27, 2018

Published: April 30, 2018

Copyright ( 92018 by authors and Scientific Research Publishing Inc. This work is licensed under the Creative Commons Attribution International License (CC BY 4.0).

http://creativecommons.org/licenses/by/4.0/

\begin{abstract}
This paper presents a three-dimensional geological reservoir model created using stochastic simulation. The oil field presented is an East African oil field formed by a structural trap. Data analysis and transformations were conducted on the properties before simulation. The variogram was used to measure the spatial correlation of cell-based facies modeling, and porosity and permeability modeling. Two main lithologies were modelled using sequential indicator simulation, sand and shale. Sand had a percentage of $26.8 \%$ and shale of $73.2 \%$. There was a clear property distribution trend of sand and shale from the southwest to the northeastern part of a reservoir. The distribution trend of the facies resembled the proposed depositional model of the reservoir. Simulations show that average porosity and permeability of the reservoir are about $20 \%$ and $1004 \mathrm{mD}$, respectively. Average water saturation was $64 \%$. STOIIP volume of $689.42 \mathrm{MMbbls}$ was calculated. The results of simulation showed that the south eastern part of the reservoir holds higher volumes of oil. In conclusion, the model gave a better geological understanding of the geology of the area and can be used for decision making about the future development of the reservoir, prediction performance and uncertainty analysis.
\end{abstract}

\section{Keywords}

Geostatistical Modeling, Stochastic Simulation, Variograms, Sequential Indicator Simulation, Sequential Gaussian Simulation

\section{Introduction}

\subsection{Reservoir Models}

$3 \mathrm{D}$ geological models are important in the petroleum field as they give a repre- 
sentation of the geology of the reservoir. A good model should be as close to the real life geological scenario as possible. "However, for oil reservoirs, the real-life scenario is not fully known except in a few data points" [1]. The rest of the model is hence based on speculation of what should occur. Geostatistical techniques are a common method used in the construction of three-dimensional reservoir models [1]. The two most commonly used forms of stochastic simulation for reservoir modeling applications are sequential gaussian simulation for continuous variables like porosity and permeability and sequential indicator simulation for discrete variables like facies. Successful models can then be used to calculate reserves and upscaled to carry out numerical simulations to predict hydrocarbon recovery and field economics over given development strategies and for uncertainty analysis studies as well.

Reservoir modeling involves the integration of different types of data as shown in Figure 1 and geological knowledge to create a model that represents the subsurface. It is an ongoing process right from the discovery of an oil field to the last stages of production and abandonment [2]. Figure 2 illustrates an integrated reservoir workflow from well data to a geological model. Most of the current research on reservoir modeling is on the different ways to combine the diverse data to create a good reservoir model (a model that accurately reflects the original data and production history). Some of the data used in reservoir modeling includes; core data, well log data, sequence stratigraphic interpretations, analog data, seismic derived attributes, trends and stacking patterns, well test and production data. Despite the diverse data are available for reservoir modeling, it is usually sparse relative to the vast inter well region that has to be modeled.

The main steps involved in reservoir modeling include; building the structural design of the reservoir, stratigraphy modeling, facies modeling within each stratigraphic layer and petrophysical properties modeling based on the facies. This is a

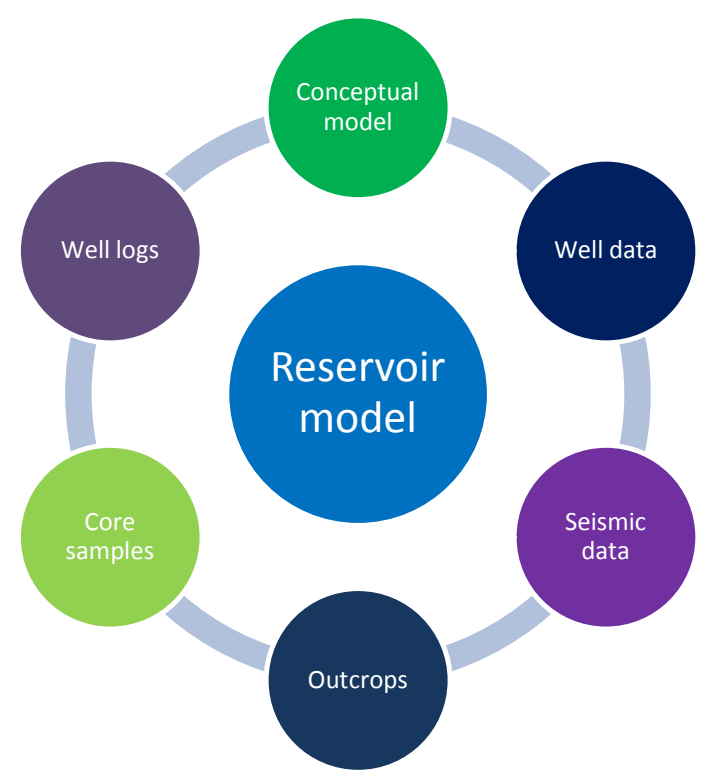

Figure 1. Data for reservoir modeling. 


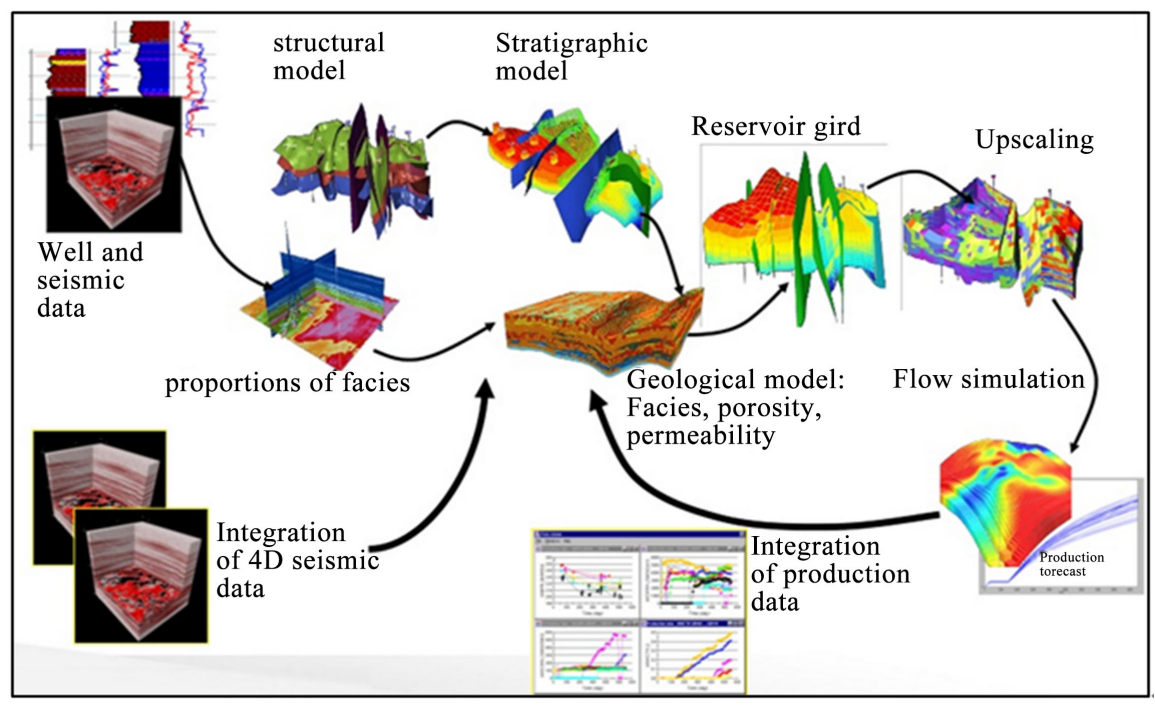

Figure 2. Integrated reservoir modeling workflow [3].

sequential approach work flow, where large scale properties are modeled first, followed by smaller uncertain properties. In the case of stochastic modeling, multiple realizations of the model can be created in order to draw statistical inferences from the set of all outcomes. The modeling steps may however vary depending on; the type of data available, time, reservoir type and human expertise.

\subsection{Importance of Reservoir Models}

Reservoir models are important tools in the petroleum industry for the following reasons;

- Representation of different kinds of data (2D and $3 D$ seismic, $4 D$ time-lapse seismic, directly sampled rock formations in form of cuttings and cores, well $\operatorname{logs}$ ) in a common format.

- Estimation of the original volumes of hydrocarbons which help in economic assesment of a reservoir and drawing up appropriate development plans.

- Optimal placement of wells.

- Input into a simulator for dynamic analysis or visualized and used to aid in decision making.

- Uncertainty analysis.

\subsection{Geostatistics}

Geostatistics is the study of phenomena that vary in space and time [4]. Some phenomena of interest to reservoir engineers include, facies, reservoir thickness, porosity, and permeability [4]. Geostatistics was started in the 1960s by Krig and Sichel in South Africa and Matheron in France. Its techniques have been applied in many fields including the oil industry.

\section{Components of Geostatistics}

(Semi) variogram analysis, characterization of spatial correlation [4]. 
Kriging, optimal interpolation; generates best linear unbiased estimate at each location; employs semi variogram model [4].

Stochastic simulation-generation of multiple equiprobable images of the variable; also employs semi variogram model [4].

Geostatistical routines are implemented in major reservoir modeling packages like Petrel and RMS to generate facies, porosity and permeability models. Geostatistical methods are optimal when data are normally distributed and stationary (mean and variance do not vary significantly in space). Significant deviations from normality and stationarity have a significant impact on the variogram [4]. The data hence has to be transformed, statistically analyzed, then back transformed at the end.

1) Variogram

Geoscience data sets are distinguished from other types of data sets in one important aspect, they exhibit spatial relationship [1]. In simple terms, neighboring values are related to each other. This relationship gets stronger as the distance between two neighbors becomes smaller. In most instances, beyond a certain distance the neighboring values become uncorrelated. This type of qualitative information needs to be defined in a suitable form so that it can be used to estimate values at unsampled locations. Variograms are used to display the variability between data points as a function of distance. It is the most widely used tool to investigate and model spatial variability of various reservoir attributes [2]. Figure 3 illustrates a variogram displaying variability between data points as a function of distance and the main components of a variogram. Usually, time and budget constraints force reservoir engineers to proceed directly to facies and petrophysical property modeling immediately. The preliminary steps of variogram calculation, interpretation, and modeling are often performed hastily or even skipped altogether. Variograms however significantly influence

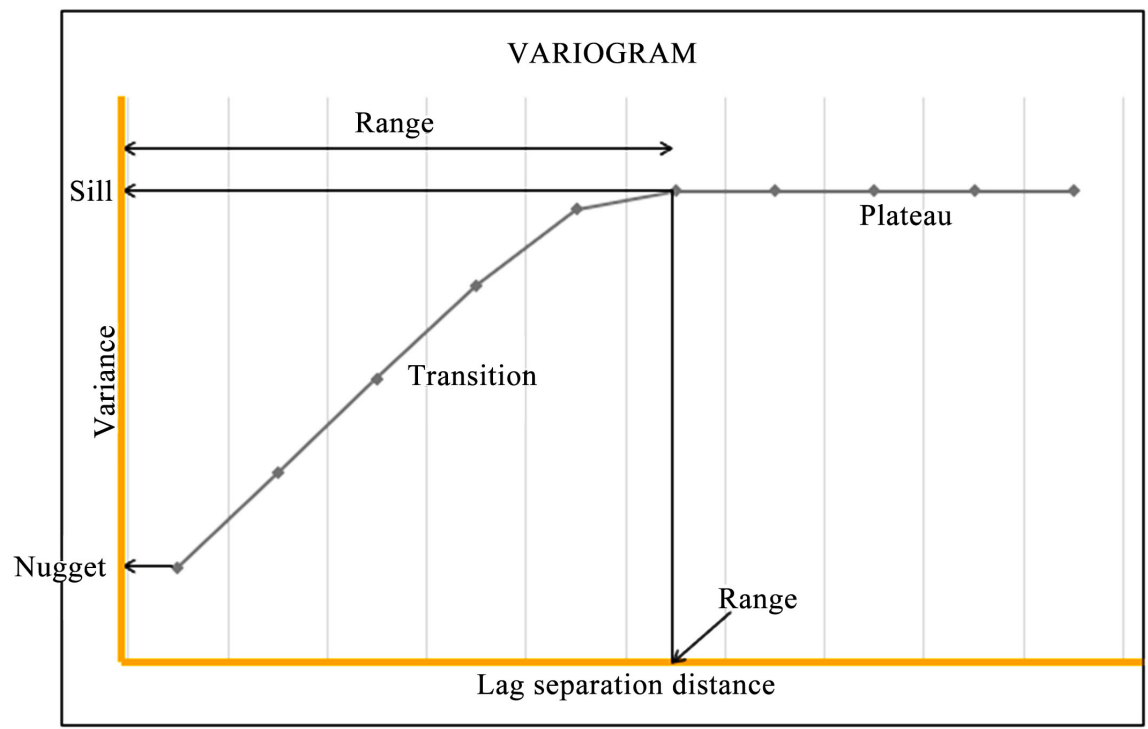

Figure 3. A variogram displaying variability between data points as a function of distance. 
the appearance and flow behavior of the final model [5]. Geoscientists and engineers have used variograms extensively as the tool to quantify the spatial relationship of attributes such as facies, porosity, and permeability. Proper variogram modeling is a key factor to obtaining a geologically sound reservoir characterization model [6].

In this paper, variogram models are used as the input for simulating geological rock facies, porosity and permeability. The technique used to simulate these attributes is stochastic simulation, which simultaneously generates petrophysical properties, porosity and permeability, consistent with the underlying facies [6].

The first step in performing the spatial analysis is to estimate the value of the variograms using the hard data, i.e., well data [6]. These variograms are commonly referred to as the experimental variograms. Estimating the experimental variograms in practice requires great care and caution due to some problems such as lack of data pairs at certain lag distance due to well spacing, and biased sampling. A common difficulty in calculating experimental variograms is the calculation of the horizontal variogram. This is due to the sparseness of the data in the horizontal direction, which is governed by well spacing [6]. Estimating vertical variograms is relatively a simple task since abundant data are sampled in the vertical direction.

In principle, experimental simulation technique will require the definition of spatial relationship, i.e., variogram, of each variable being simulated in three main directions, namely major, minor, and vertical directions. Both major and minor variograms are in the horizontal direction [6].

Variogram modeling is the process of representing the experimental variogram with an acceptable mathematical model that can be input in the stochastic simulation technique being used [6].

$A$ variogram is basically a display of the mean square difference between two values as a function of their increment [7]. The value of a variogram is calculated by

$$
\gamma(h)=\frac{\sum_{i=1}^{n_{h}}\left(x_{i}-x_{i+h}\right)^{2}}{2 n_{h}}
$$

where, $\gamma(h)$ is a semi variogram $2 \gamma(h)$ is variogram, $n_{h}$ is the number of pairs of points with the distanceh from each other participating in the variogram.

$x_{i}$ is a grade in point $i$.

$X_{i+h}$ is grade in a point with distance $h$ from the point $i$.

The terms variogram and semi variogram may be used interchangeably.

a) Characteristics of the Variogram

Sill: The semi variance value at which the variogram levels off. Data is no longer auto correlated. Also used to refer to the "amplitude" of a certain component of the semi variogram.

Range: The lag distance at which the semi variogram (or semi variogram component) reaches the sill value.

Nugget: The semi variance where the separation distance is zero. 
Plateau: The part of the variogram model where an increase in separation distance does not change the variogram value.

The lack of data, which makes the variogram important, also makes it difficult to calculate, interpret, and model a reliable variogram. Practitioners have been aware of this problem for some time with no satisfactory solution. Analogue data available from better-drilled fields, outcrop studies, or geological process modeling provide valuable input, however, this data must be merged with field-specific calculations to be useful [5].

2) Stochastic Simulation

Geostatistical model-building algorithms such as sequential Gaussian simulation, sequential indicator simulation, and truncated Gaussian simulation take an input variogram model and create a 3-D model constrained to local data and the variogram model. The variogram has an extremely important role to play in the appearance and flow behavior of 3-D models due to the sparse data available for petroleum reservoir characterization. Stochastic simulation is a way of property modeling in which multiple equiprobable realizations of the properties are generated instead of simply estimating the mean. Unlike the smoothing effect of kriging, stochastic simulation adds back in some noise to undo the smoothing effect. This gives a better representation of the natural variability of the property [5].

The two frequently used forms of simulation for reservoir modeling applications are sequential gaussian simulation for continuous variables like porosity and permeability and sequential indicator simulation for discrete variables like facies. Figure 4 shows the main steps followed in sequential gaussian simulation.

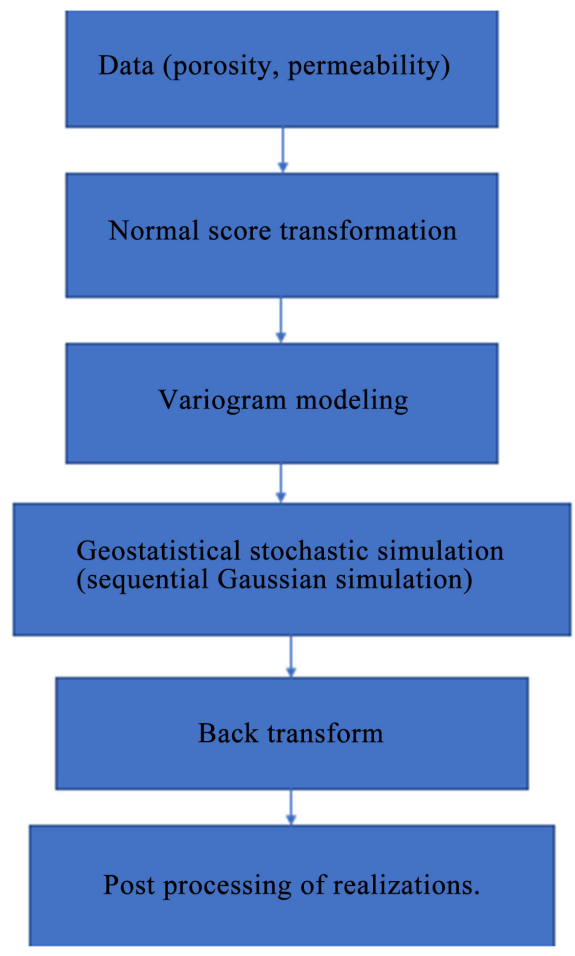

Figure 4. Sequential gaussian simulation flowchart [9]. 
The basic idea of sequential gaussian simulation (SGS) is very simple. Kriging gives us an estimate of both the mean and standard deviation of the variable at each grid node, meaning we can represent the variable at each grid node as a random variable following a normal (Gaussian) distribution. Rather than choose the mean as the estimate at each node, SGS chooses a random deviate from this normal distribution, selected according to a uniform random number representing the probability level. Sequential indicator simulation (SIS) is very similar to sequential gaussian simulation, except that indicator kriging is used to build up a discrete cumulative density function for the individual categories at each case and the node is assigned a category selected at random from this discrete cumulative density function [8].

\subsection{Statement of Problem}

Companies in the petroleum industry have to invest very large sums of money in exploration, development, and exploitation of the petroleum reservoirs. To reduce costs and manage the risks involved with production, companies have to draw up impeccable development strategies. To do this, they need to have knowledge of the reservoir's geological settings, reservoir heterogeneity conditions, discontinuity and continuity of the reservoir flow with consideration of fault arrangements and quantity of a recoverable hydrocarbons. Reservoir models are currently the most efficient tools in describing reservoirs. With a proper understanding of the reservoir, oil companies are able to make good development decisions and reduce most of the production challenges that come about as a result of lack of knowledge of the reservoir.

The field under study is a new field yet to start production hence a clear understanding of its geology and reserve potential is necessary.

\subsection{Geological Setting}

The field under study is an East African oil field, formed by a structural trap. The field is a green field yet to start production in the coming years.

\subsection{Objectives of the Study}

To build a representative three-dimensional geological model of the reservoir using stochastic simulation.

To calculate the ultimate reserve potential of the reservoir.

\section{Materials and Methods}

Different well data types are used to create the model using petrel software. Reservoir modeling proceeds sequentially. Large-scale bounding surfaces are modeled, then facies, and then petrophysical properties such as porosity and permeability. The variogram is needed for stochastic modeling of surfaces and petrophysical properties. Facies modeling, however, maybe performed with object-based techniques, which do not require the use of a variogram. The impor- 
tance and relevance of object-based methods do not diminish the importance of thevariogram for a large fraction of reservoir modeling algorithms [5]. In this paper, sequential indicator simulation was used to model the facies hence the variograms were used. The model was created using the following steps;

\subsection{Structural Modeling}

It is basically defining the architectural design of the reservoir, fault compartmentalization, and a grid network to accommodate the data. Fault modeling is an important aspect of structural modeling. They define the breaks in the grid and hence affect fluid flow in the reservoir.

\subsubsection{Fault Modeling}

Fault data was imported in form of fault sticks as shown in Figure 5 and eleven faults have been modeled. The fault model is shown in Figure 6 .

\subsubsection{Pillar Gridding}

Pillar gridding defines the horizontal scale of the reservoir surfaces (top, mid and bottom surface). The grid was generated using the modeled fault model. The setting for grid distance in I and J direction was set to 100 meters in I direction and 100 meters in J direction. Figure 7 shows the pillar grid created in the study, Figure 8 shows a three dimensional model with the faults while Figure 9 shows the compartmentalized model without the faults.

\subsection{Stratigraphy Modeling}

Stratigraphy modeling involves vertical layering of the 3D grid using horizons and layers. This is the characterization of the internal structure of the model. It involves building the vertical layering in the model. The vertical sequence of the layers mirrors the original lateral distribution of sedimentary environments and is guided by the interpreted depositional surfaces on seismic sections.

\section{Horizons, Zones and Layers}

Three horizons were modeled. The reservoir was then subdivided into 8 zones based on well tops. Several layers were then added within each zone. Figure 10 shows one of the horizons created to mirror the original sedimentary layer, Figure 11 shows the different zones created by the horizons and Figure 12 shows an up-close image of the layers created within the zone.

\subsection{Property Modeling}

\subsubsection{Introduction}

Property modeling is the assignment of appropriate lithological (facies modeling) and petrophysical properties to each block. Facies are lithological units with particular geological characteristics. They can be considered as an elementary part of the reservoir model. Facies are modeled first because they are of a great influence to the petrophysical properties. The modelled facies constrain the the variability 


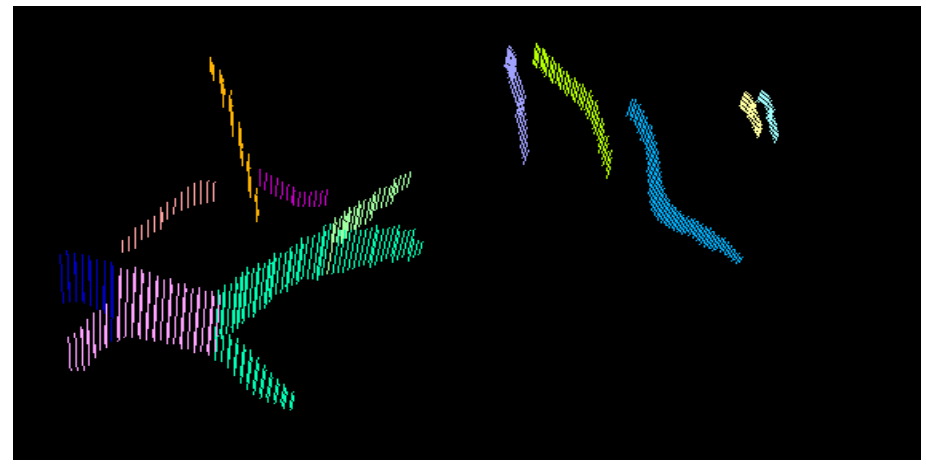

Figure 5. Imported fault sticks.

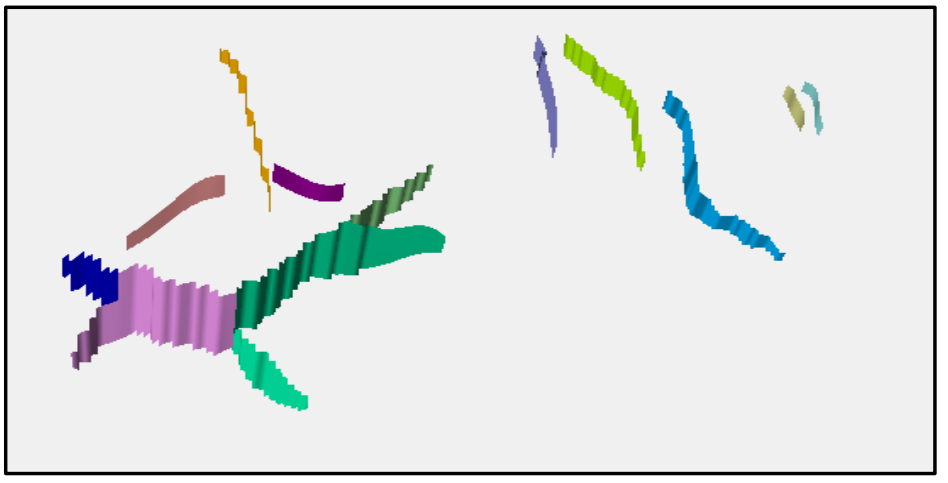

Figure 6. Fault model.

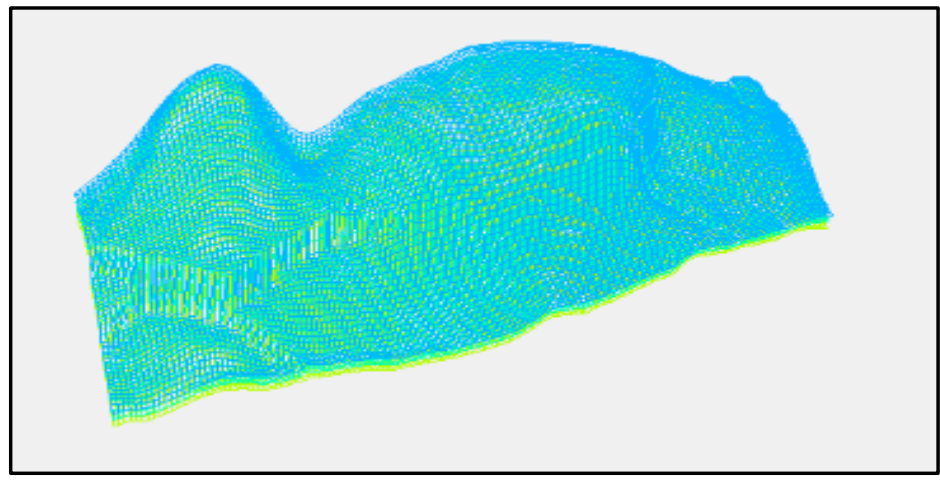

Figure 7. A grid network to accommodate data.

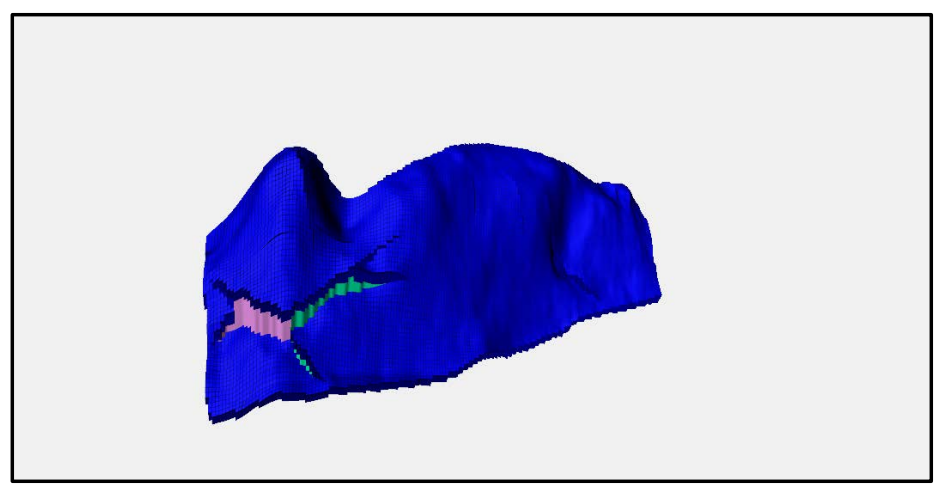

Figure 8. Three-dimensional model with faults. 


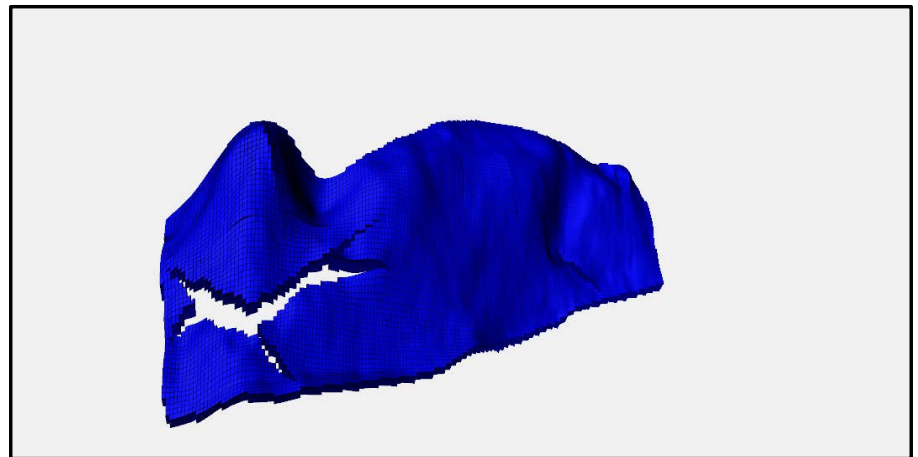

Figure 9. Fault compartmentalization.

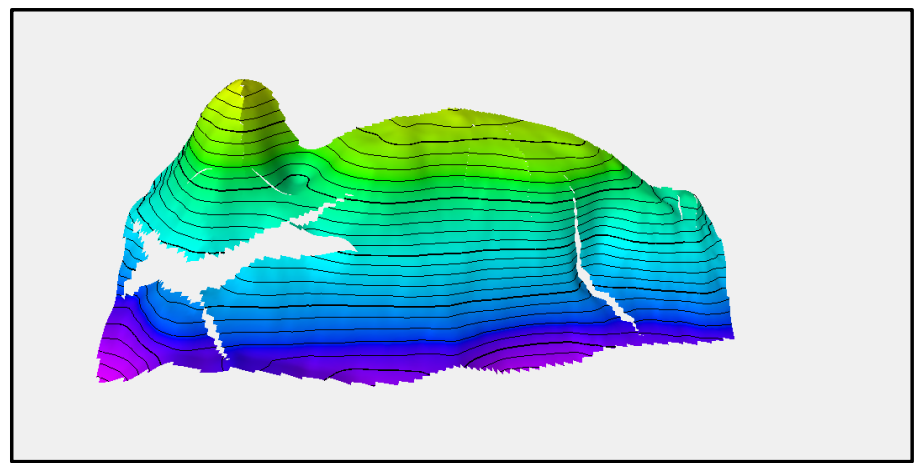

Figure 10. Horizon created from surface.

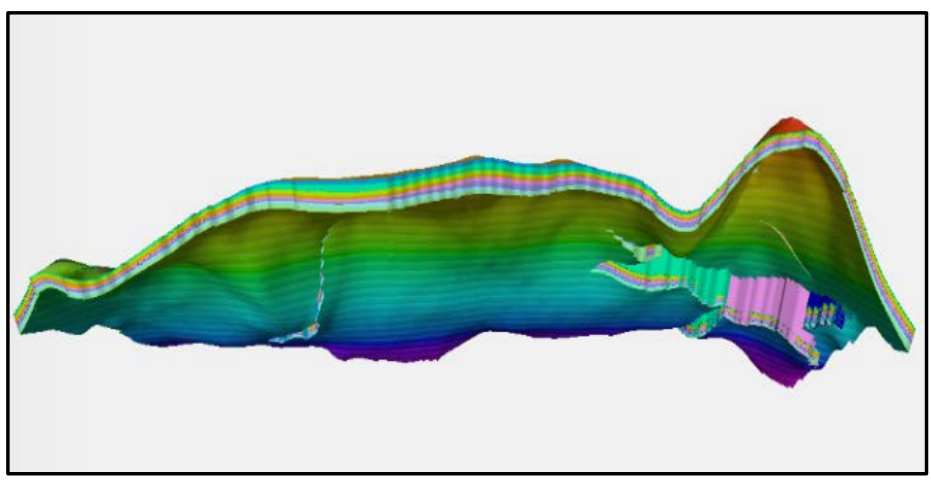

Figure 11. Reservoir zones.

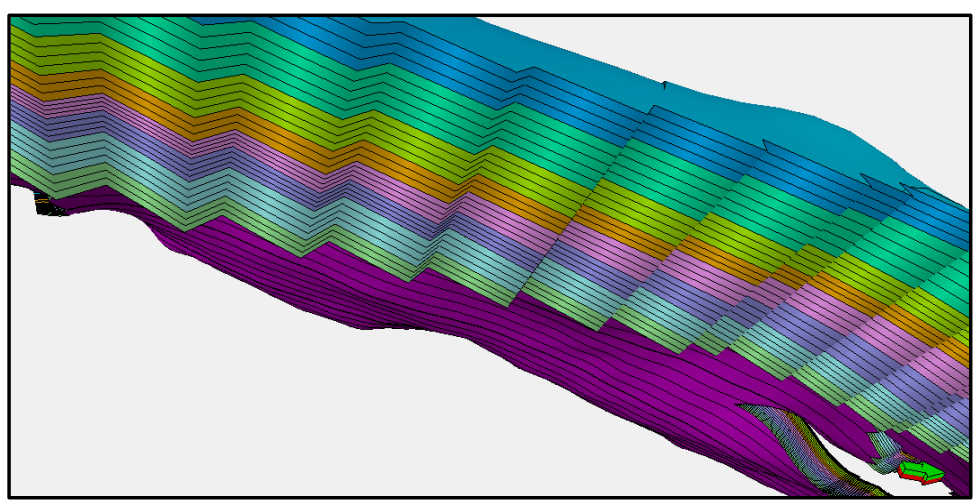

Figure 12. Reservoir layers. 
range of porosity and permeability. Saturation functions also depend on the facies. Facies distribution throughout the entire reservoir can be performed using statistical methods such as sequential indicator simulation.

Petrophysical properties; porosity, permeability and water saturation are the main properties needed to characterise the reservoir. Porosity is defined as the pore space volume. Only the effective porosity is advised to be modelled. Total porosity includes the porosity that will never be accessed. Permeability is a measure of the ease with which a fluid can flow through the pore spaces of a rock. Porosity and permeability control fluid storage and flow in a reservoir whereas fluid saturations and porosity control the amount of the hydrocarbons stored. Porosity and permeability determine the reservoir quality. The reservoir quality of a sedimentary rock is the product of the texture and composition of the original sediment. The original texture and composition are then modified by burial, compaction, diagenesis, and deformation. Core data and well logs are the main sources of the petrophysical values. Sequential guassian simulation is used to distribute the petrophysical properties within the facies and stratigraphic layers in the entire reservoir. The procedure is repeated with different random seeds to create multiple realizations (DjebbarTiab and Erle C Donaldson).

\subsubsection{Lithology and Petrophysical Modeling}

Figure 13 shows the bulk volume of a structure model which has a minimum value of 0 as shown in Table 1 . This implies the model is good and property modeling can hence proceed.

Lithology was defined and identified from SP and GR logs using alpha mapping method formula. The data was then up scaled due to the large reservoir description grid blocks compared to the support volume of the measurement. Upscaling was the first step in distributing properties values in all cells. The upscaled values were then used for the horizontal facies distribution using sequential indicator simulation in Petrel.

The petrophysical properties were simulated with Sequential Gaussian Simulation (SGS). Data Analysis was conducted on each property. Porosity underwent a normal score transformation before Sequential Gaussian Simulation. Permeability underwent a logarithmic transformation before normal score transformation.

\section{Results and Discussion}

\subsection{Facies Interpretation}

From the $\log$ analysis shown in Figure 14 and Figure 15, we see that the well penetrates a sequence of sand and shale. This shows there were low stand events when sedimentation was dominated by fluvial processes and high stand events when sedimentation was dominated by lacustrine processes. Shale units are thicker than the sand units. 
Table 1. Bulk volume statistics.

\begin{tabular}{cccc}
\hline \multicolumn{4}{c}{ BULK VOLUME STATISTICS } \\
\hline Axis & Min & Max & Delta \\
X & $240,548.51$ & 252960.52 & $12,412.01$ \\
Y & $130,719.79$ & 149521.71 & $18,801.92$ \\
$Z$ & -3544.14 & -2049.17 & 1495 \\
Bulk volume & 0 & 162,770 & 162,770 \\
\hline
\end{tabular}

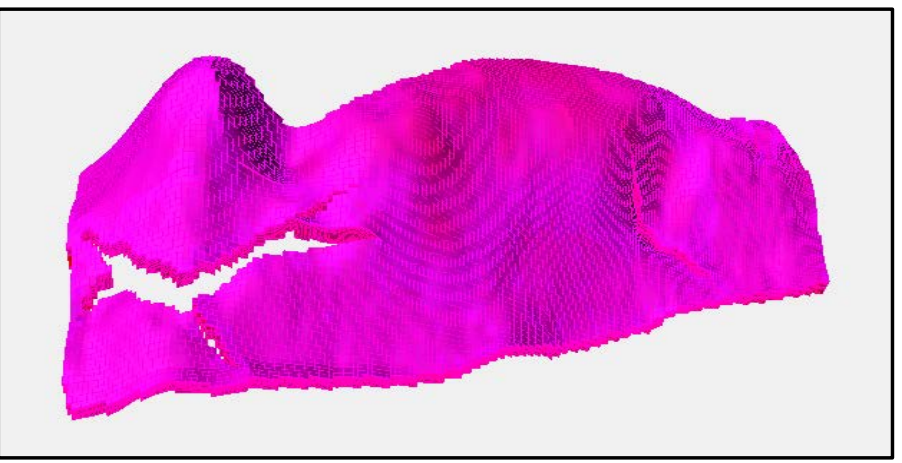

Figure 13. Bulk volume.

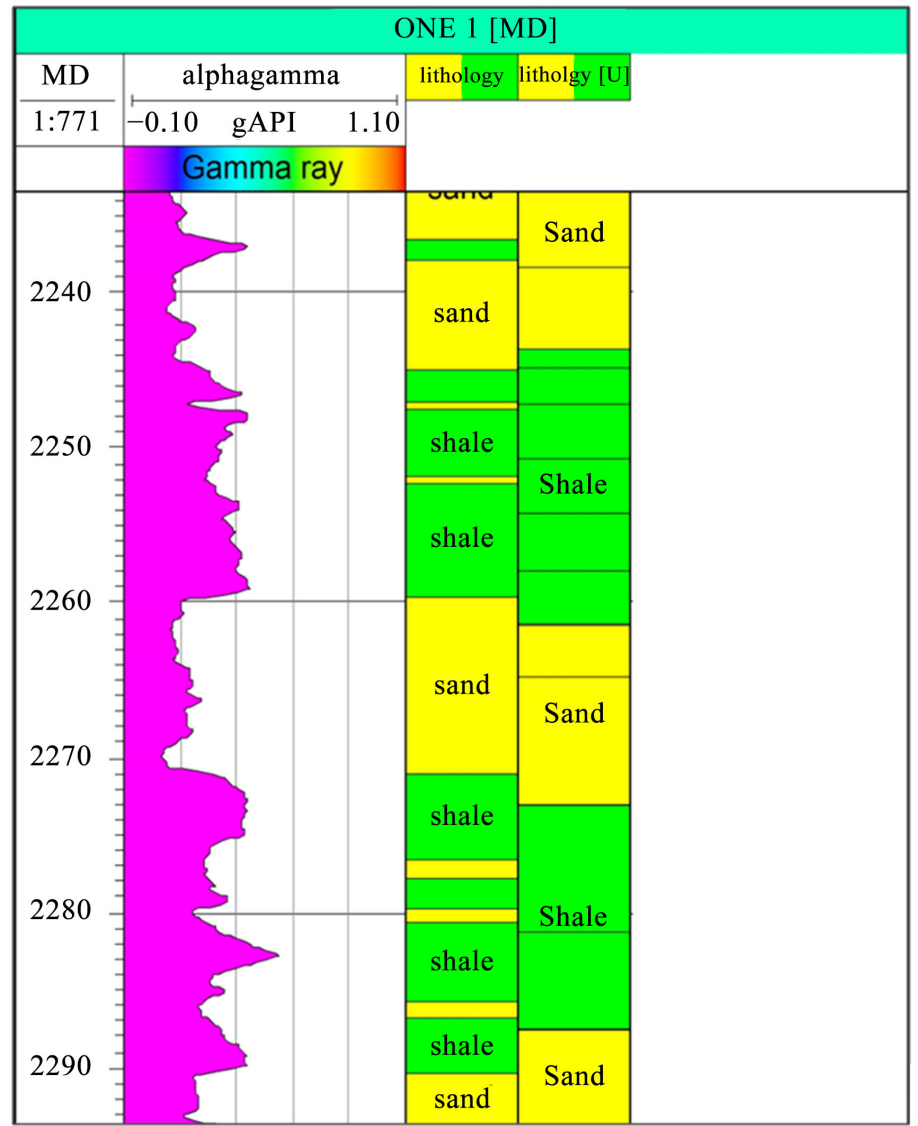

Figure 14. Well log plot and resulting lithology calculations and upscaled values of well one. 


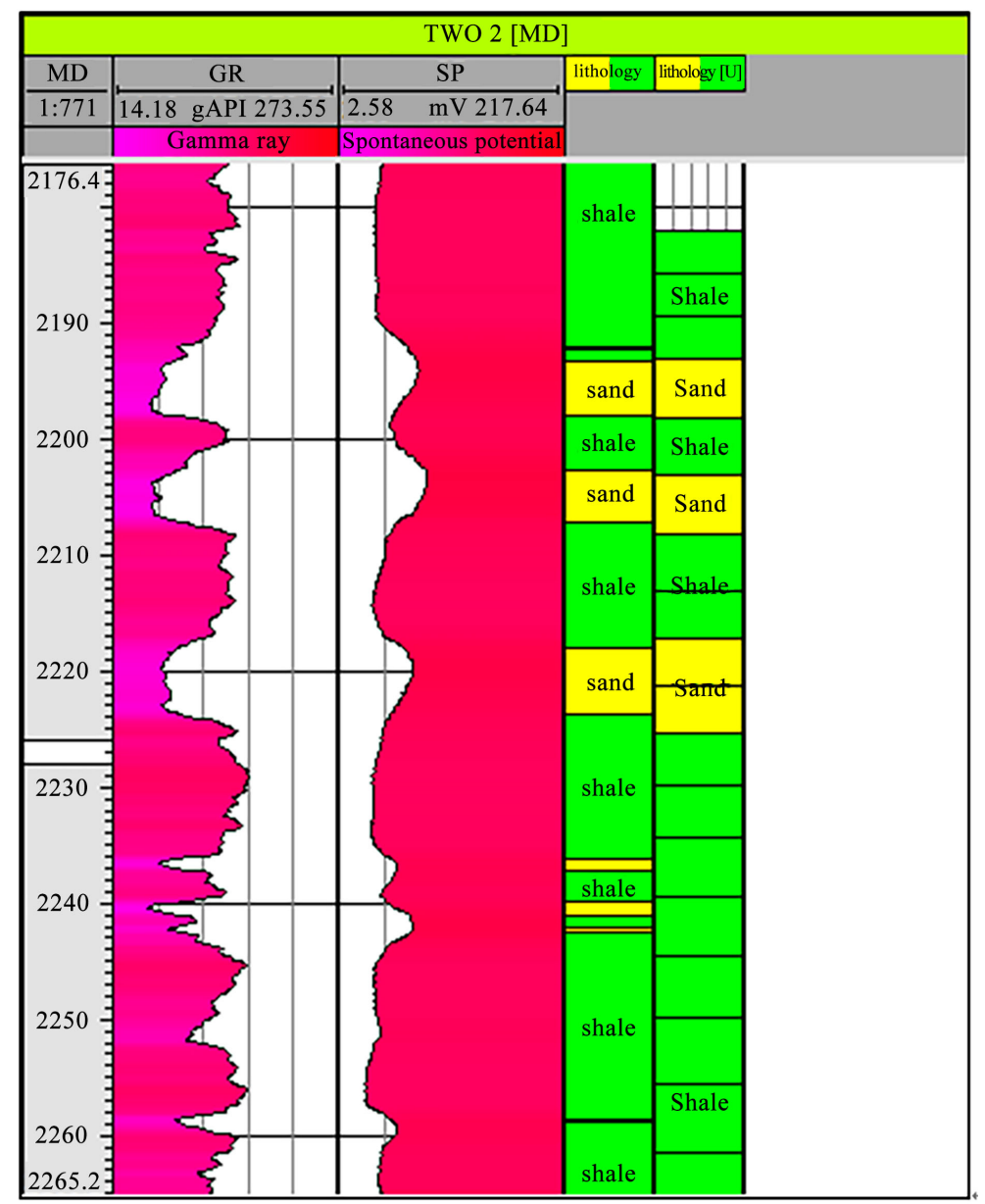

Figure 15. Well log plot and resulting lithology calculations and upscaled values of well two.

\subsection{Facies Model}

Based on sedimentary facies analysis on each well, two basic facies are defined for facies modelling: Shale and sand. Sand had a percentage of $26.8 \%$ and shale of $73.2 \%$. There was a clear property distribution trend of sand and shale from the southwest to the northeastern part of the reservoir. The distribution trend of the facies resembled the proposed depositional model of the reservoir. Variograms models are shown in the Figures 16-18. Figure 16 displays the vertical direction variogram, while Figure 17 and Figure 18 display the minor and major direction variograms respectively. The proposed depositional facies model is displayed in Figure 19. Figure 20 shows the modeled facies property model and slices through the property model is shown in Figure 21. The histogram displaying the property, upscaled and original well logs of lithology is shown in Figure 22. The statistics for the lithology distribution is shown in Table 2

\section{Petrophysical Modelling}

Simulations show that average porosity of the reservoir is about $20 \%$. Figure 23 shows the normal transformation of porosity before simulation. Figure 24 displays the vertical direction variogram for porosity and Figure 25 displays the 
Table 2. Statistics for lithology distribution.

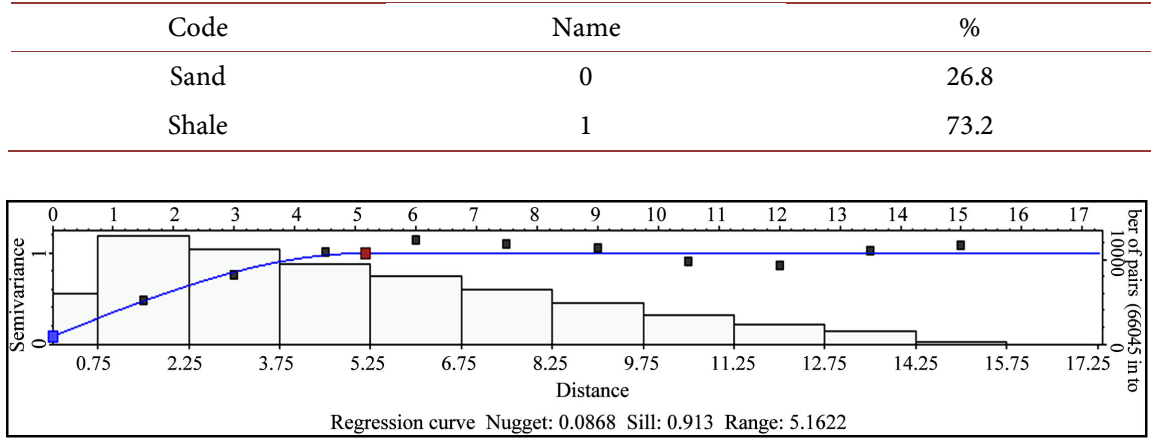

Figure 16. Vertical direction variogram-Facies.

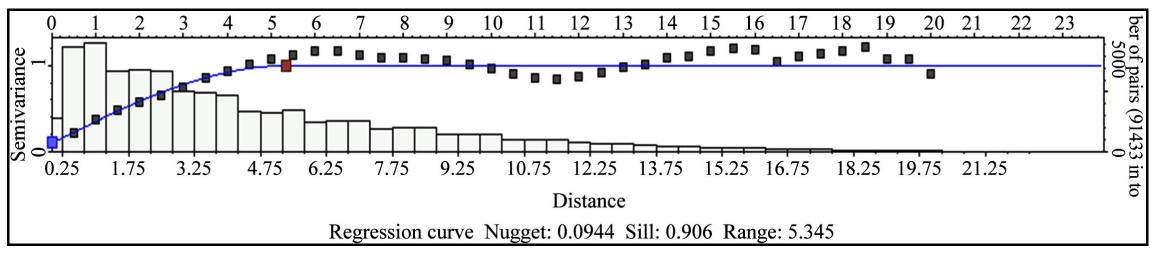

Figure 17. Minor direction variogram-Facies.

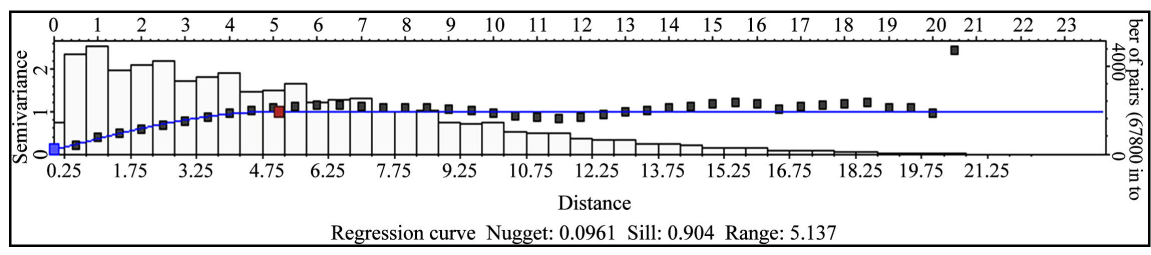

Figure 18. Major direction variogram-Facies.

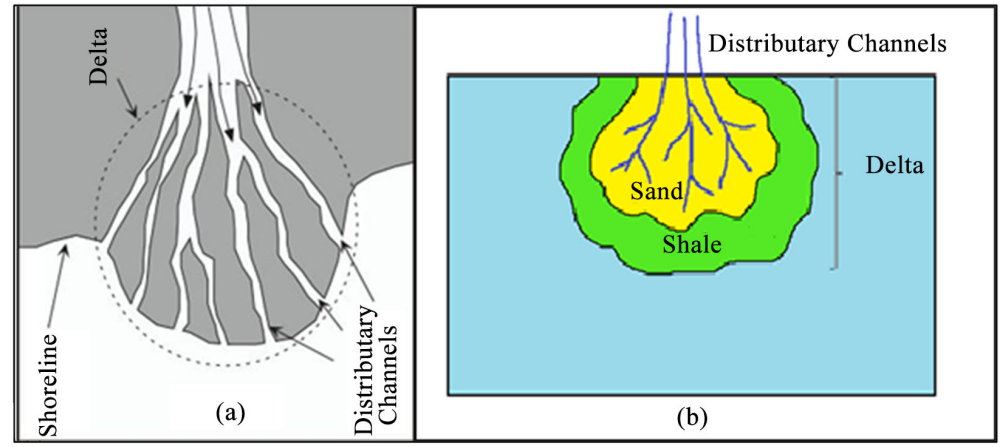

Figure 19. (a) Proposed depositional model [10] and (b) cartoon of depositional model.

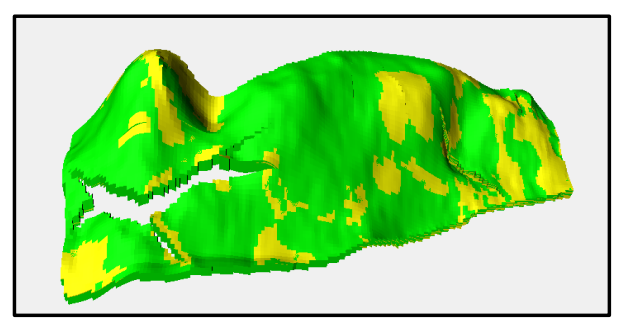

Figure 20. Lithology facies model generated by sequential indicator simulation. 


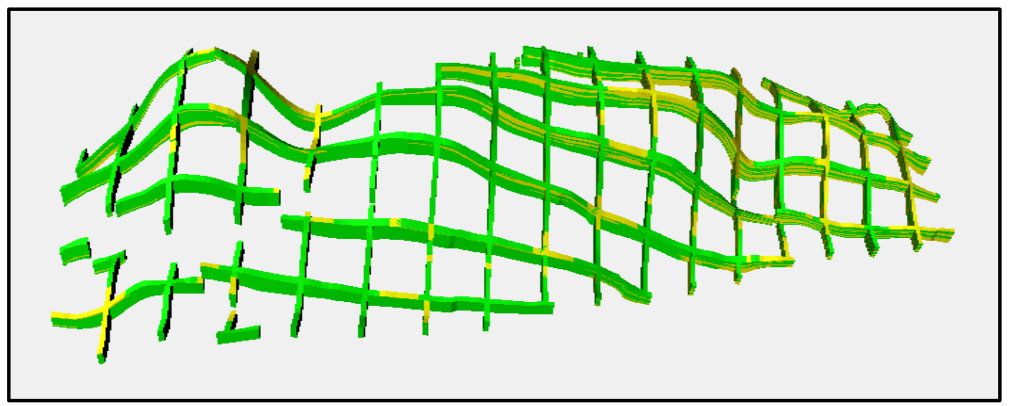

Figure 21. Slice structure of lithology.

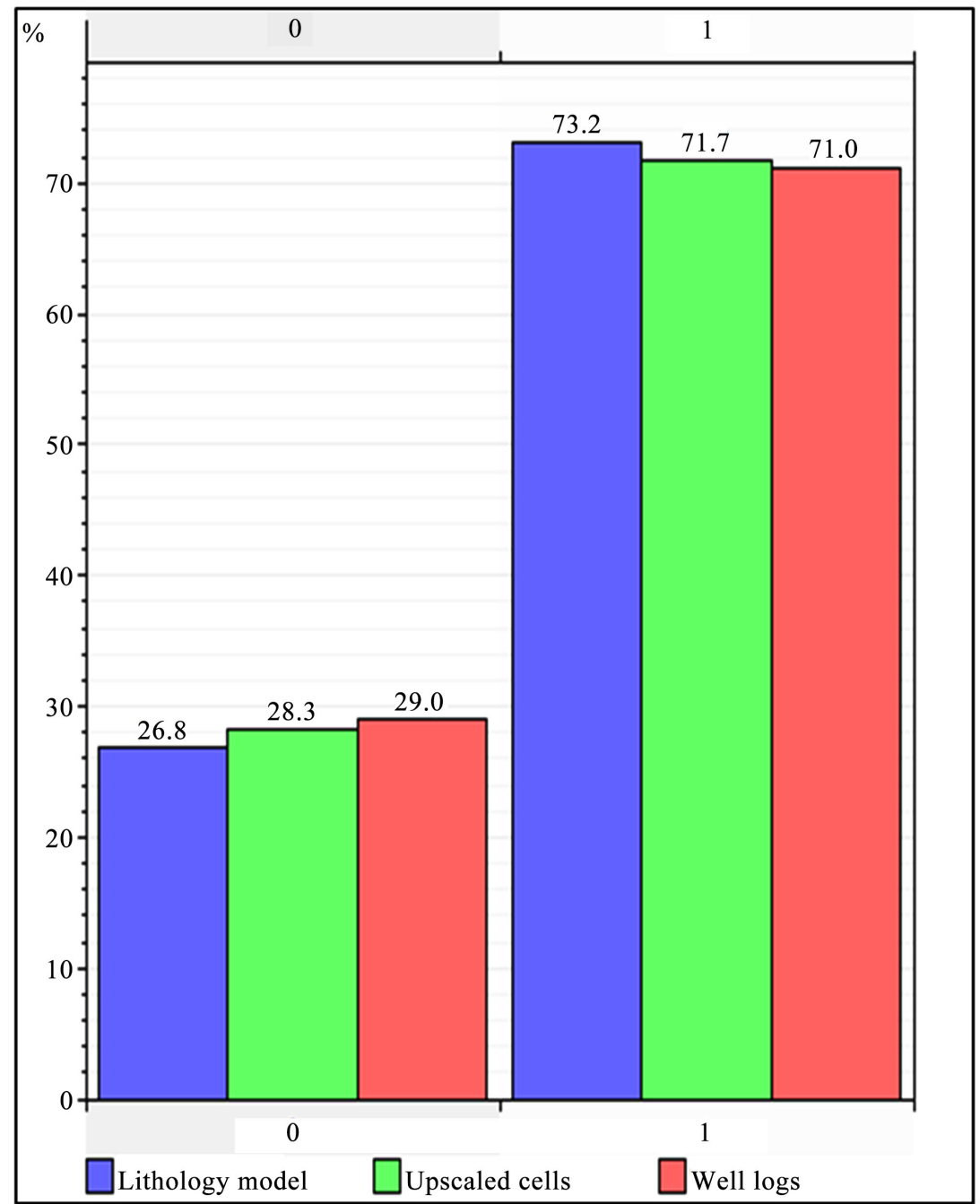

Figure 22. Property, upscaled and original well logs of lithology.

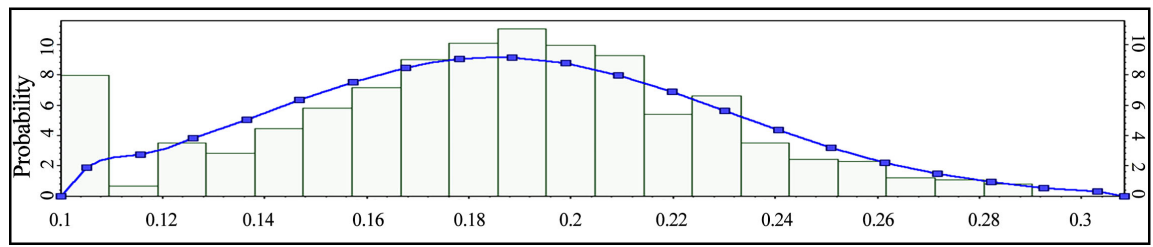

Figure 23. Normal transformation of porosity. 


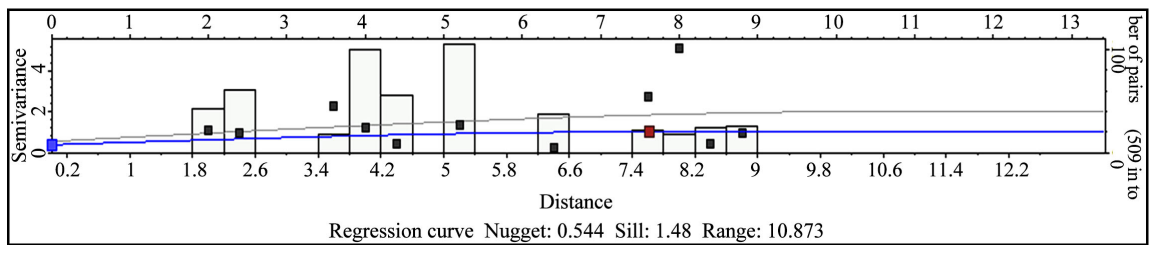

Figure 24. Vertical direction variogram-Porosity.

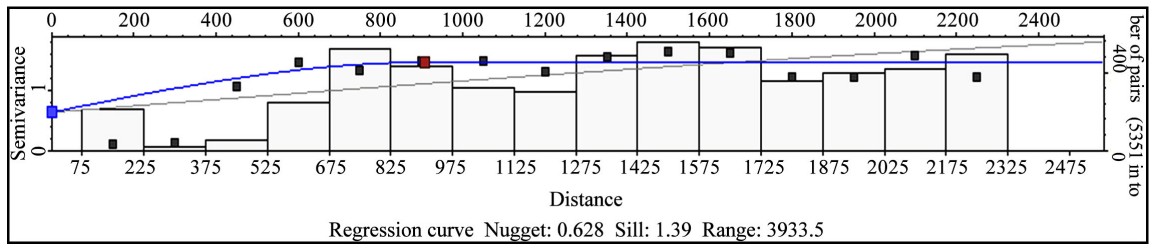

Figure 25. Minor direction variogram-Porosity.

horizontal direction variogram for porosity modeling. Figure 26 shows the three-dimensional porosity model and its slice structure is displayed in Figure 27. Figure 28 shows the porosity map.

The permeability of the reservoir is about $1004 \mathrm{mD}$. Figure 29 displays the vertical direction variogram for permeability, while Figure 30 and Figure 31 display the major and minor direction variograms for permeability respectively. The three-dimensional permeability model is shown in Figure 32, and its slice structure in Figure 33.

The water saturation of the reservoir is about $64 \%$. Figure 34 shows the normal transformation of water saturation before simulation. The vertical direction variogram for water saturation is displayed in Figure 35, while the major and minor direction variogram for water saturation are displayed in Figure 36 and Figure 37 respectively. The three-dimensional water saturation model is shown in Figure 38 and its slice model is illustrated in Figure 39. The water saturation map is displayed in Figure 40.

NTG was also modeled to isolate the productive and non-productive parts of the reservoir. Figure 41 displays the vertical direction variogram for NTG while Figure 42 displays the minor direction variogram for NTG. The three-dimensional NTG model is shown in Figure 43 and the NTG model slice structure is shown in Figure 44. Figure 45 shows the NTG map and Figure 46 shows the NTG histograms for property and upscaled values.

In volumetric calculations, the amount of reserves in the reservoir is estimated to 689.42 million barrels. Most of the oil was in the southeastern part of the reservoir.

\section{Conclusions}

This paper has presented a case study of 3D modeling using geostatistical techniques. From the successful creation of the 3D model we can conclude that;

Two main lithologies are present in the reservoir, sand and shale.

Sand had a percentage of $26.8 \%$ and shale of $73.2 \%$. 


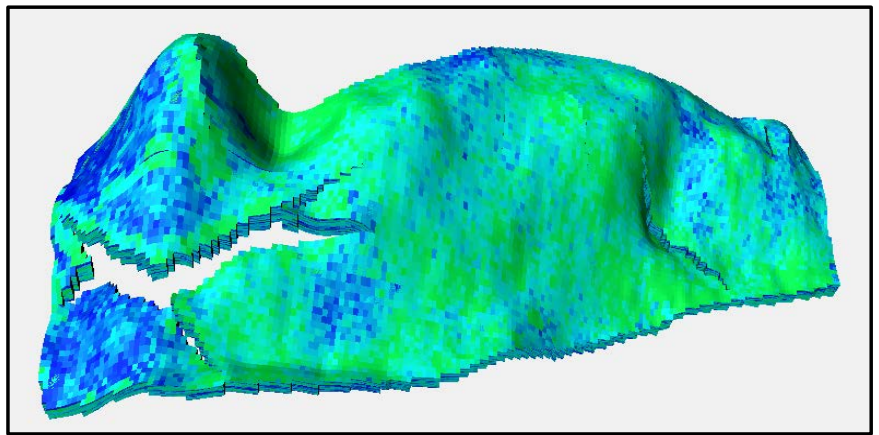

Figure 26. Three-dimensional porosity model.

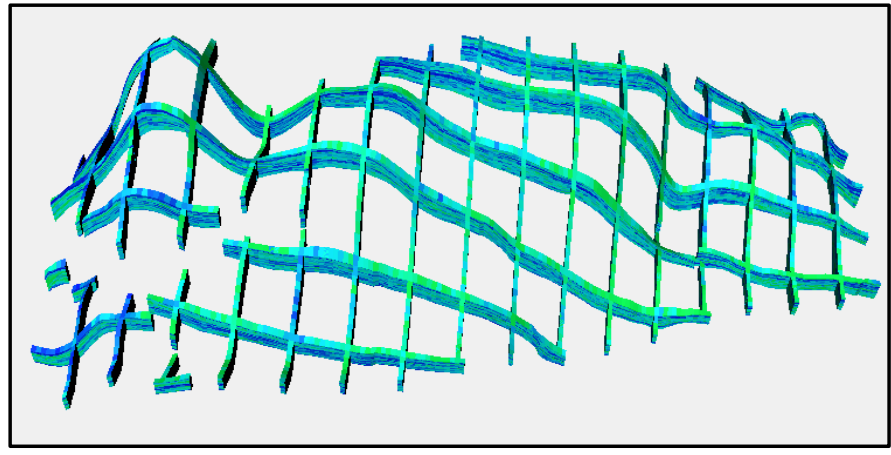

Figure 27. Slice structure of porosity model.

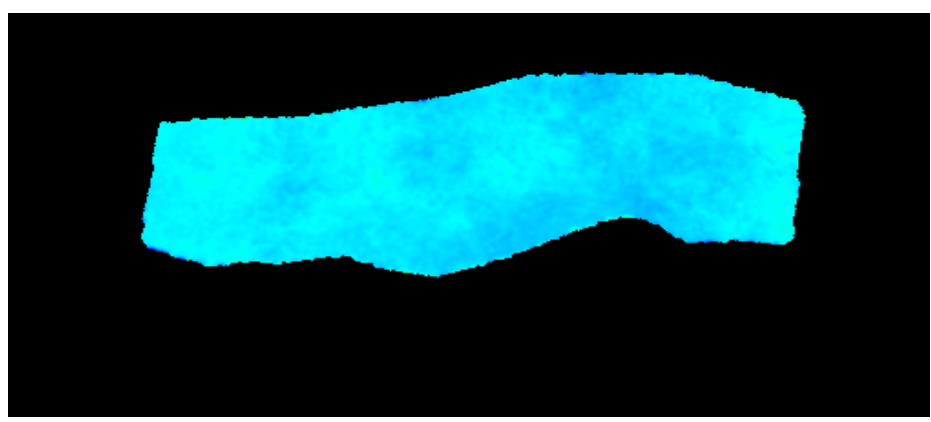

Figure 28. Porosity map.

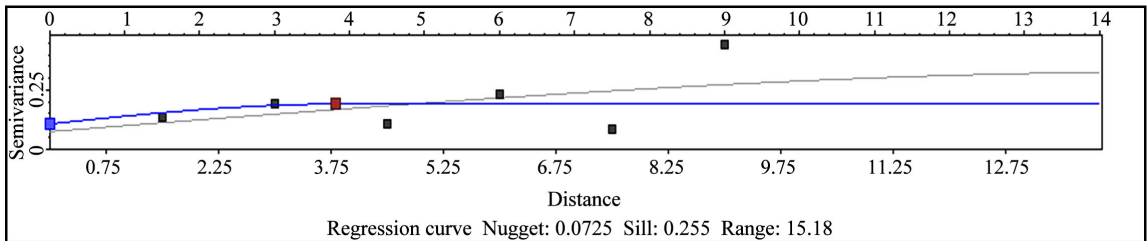

Figure 29. Vertical direction variogram-Permeability.

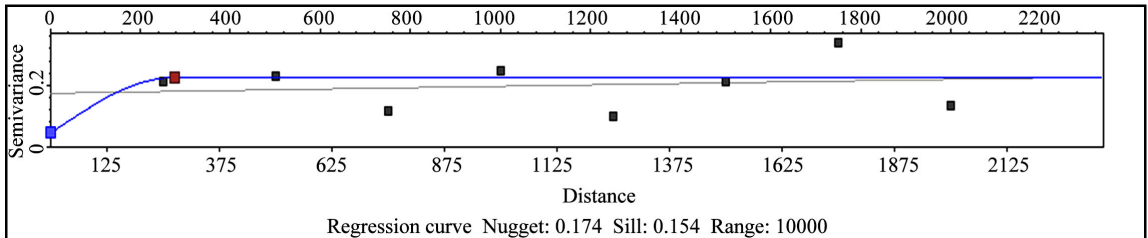

Figure 30. Major direction variogram-Permeability. 


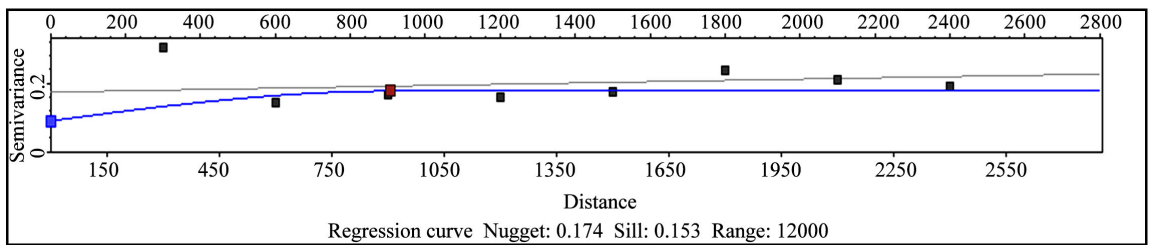

Figure 31. Minor direction variogram-Permeability.

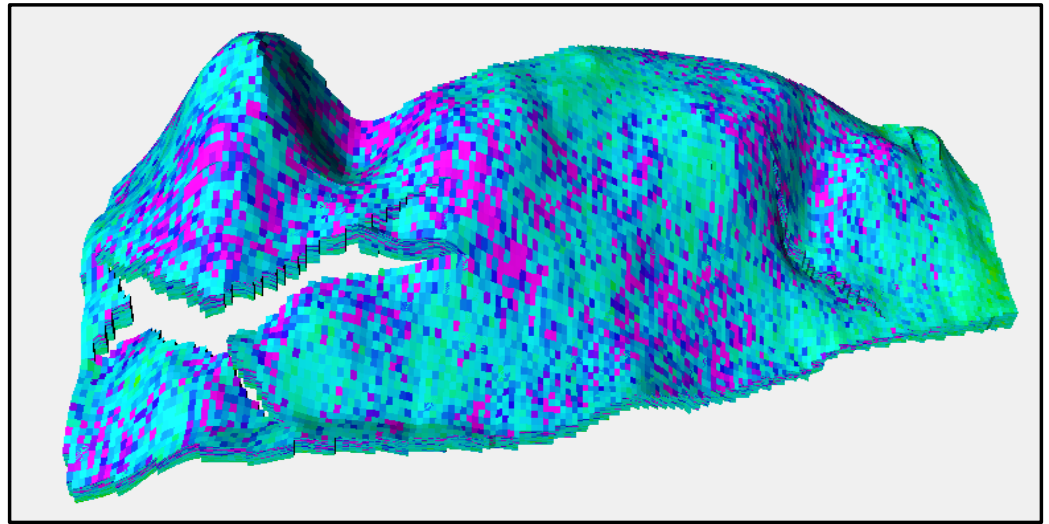

Figure 32. Three-dimensional Permeability model.

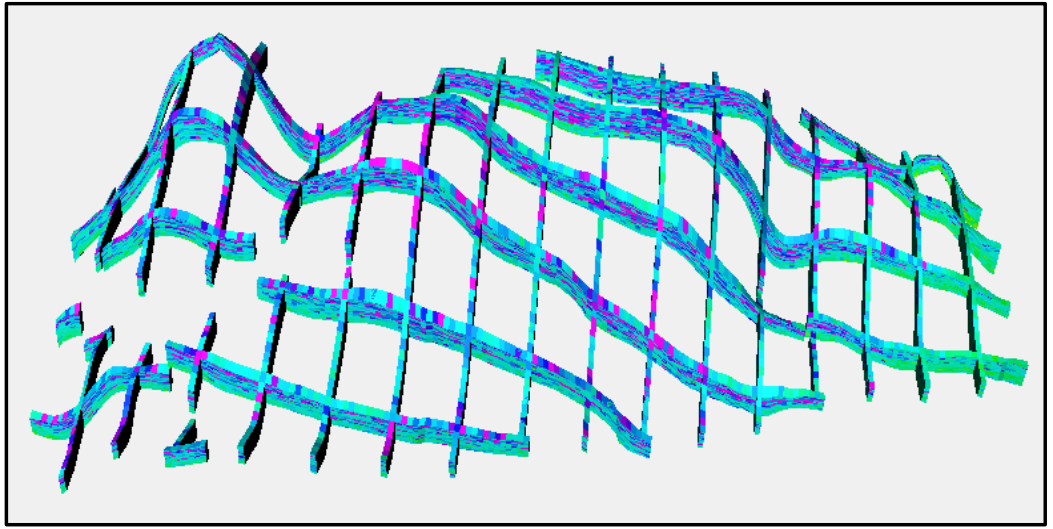

Figure 33. Slice structure of permeability model.

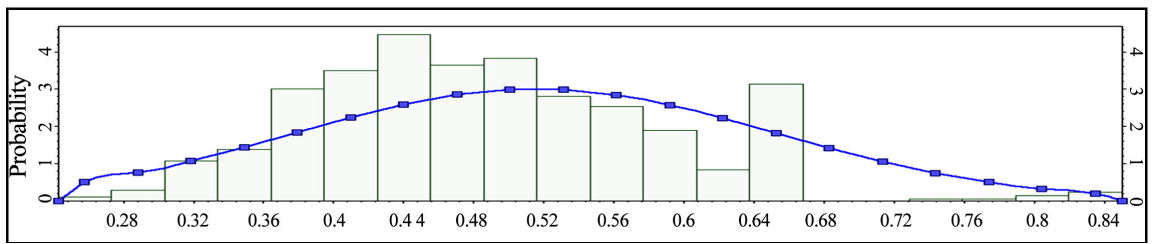

Figure 34. Normal transformation of water saturation.

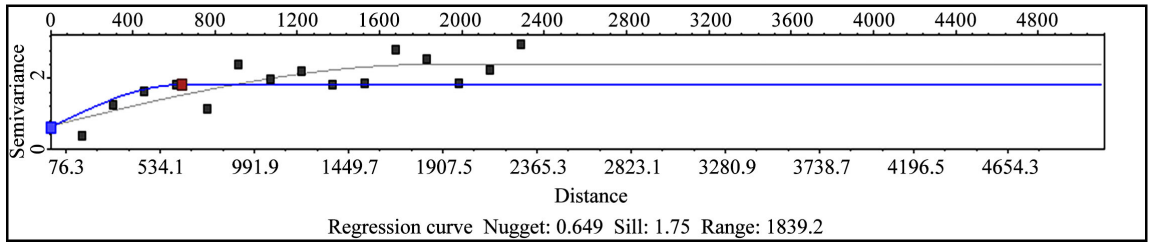

Figure 35. Vertical direction variogram-water saturation. 


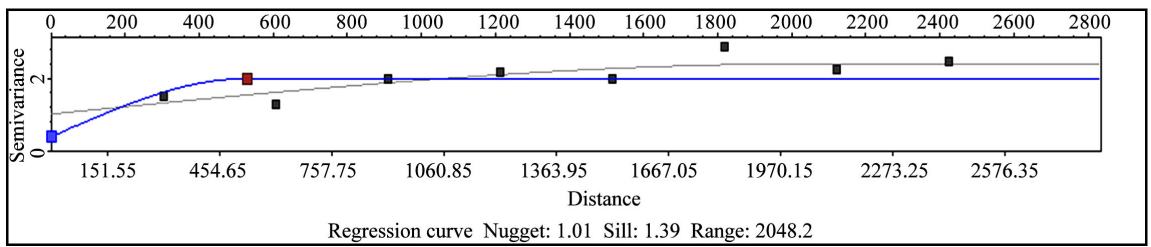

Figure 36. Major direction variogram-water saturation.

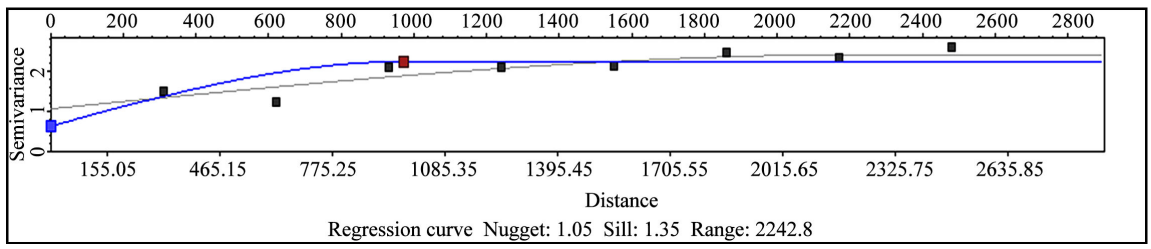

Figure 37. Minor direction variogram-water saturation.

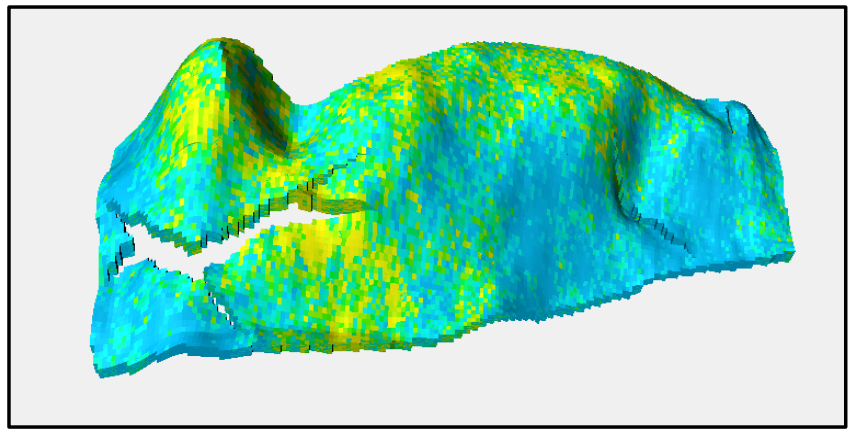

Figure 38. Three-dimensional water saturation model.

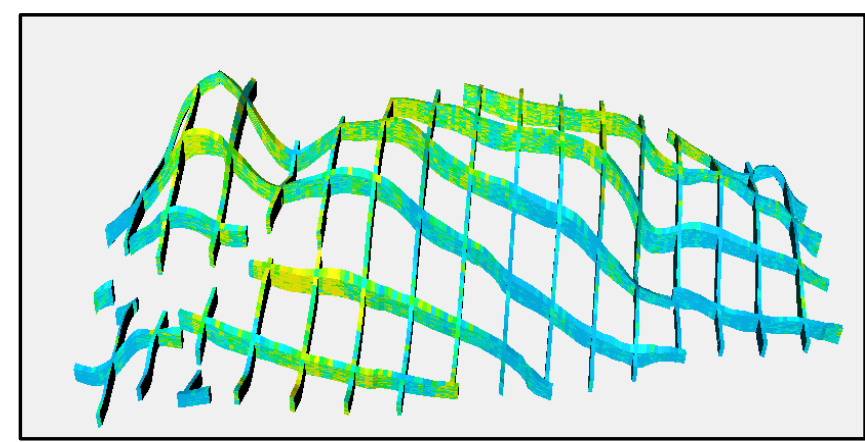

Figure 39. Slice structure of water saturation model.

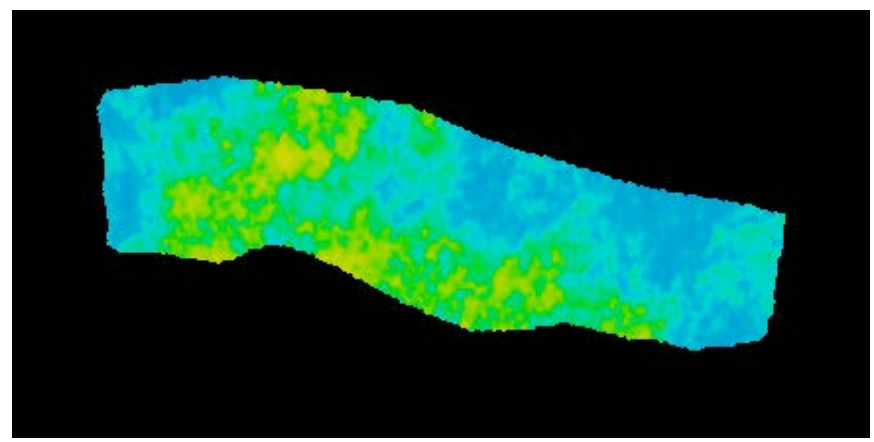

Figure 40. Water saturation map. 


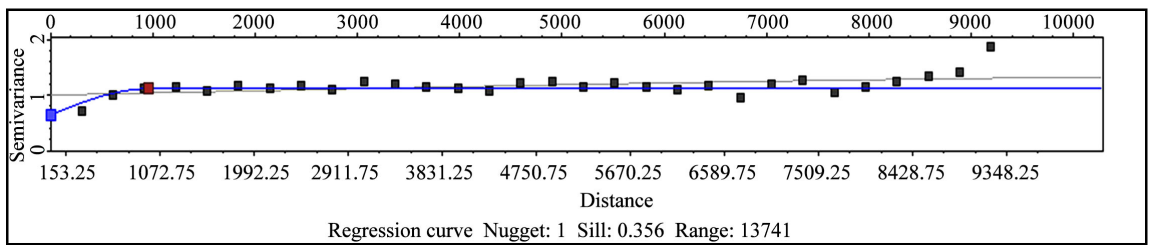

Figure 41. Vertical direction variogram-NTG.

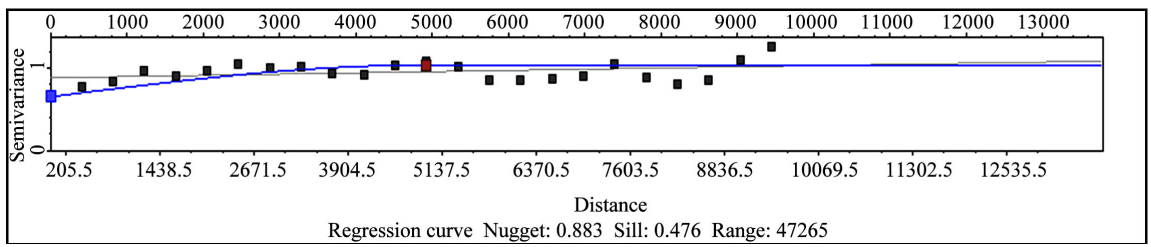

Figure 42. Minor direction variogram-NTG.

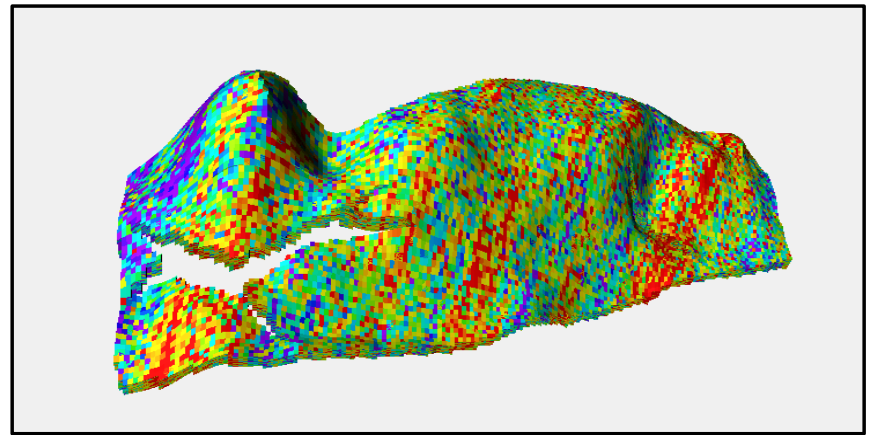

Figure 43. Three-dimensional NTG model.

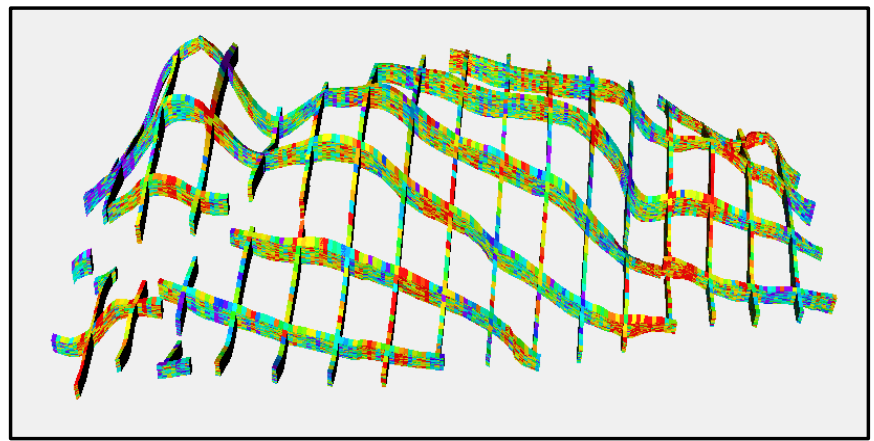

Figure 44. NTG model slice structure.

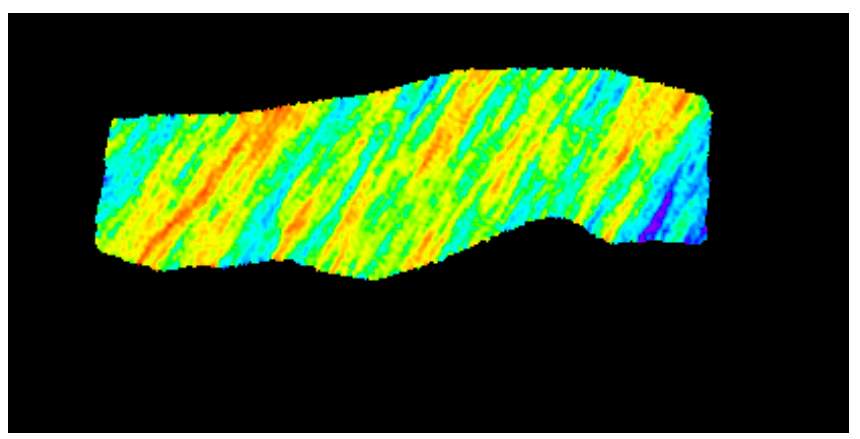

Figure 45. NTG map. 


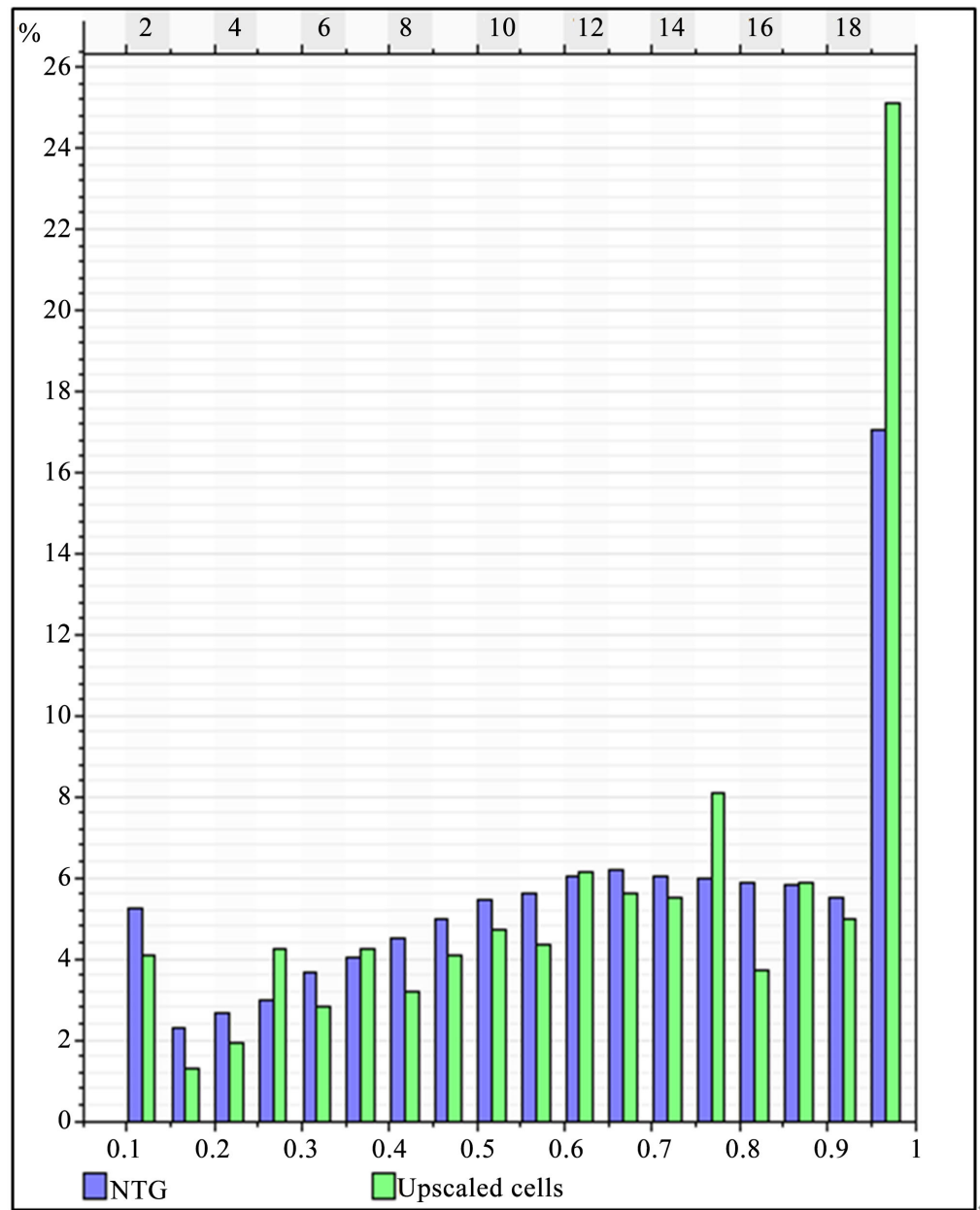

Figure 46. NTG histograms for property and upscaled values.

The average porosity and permeability of the reservoir are about $20 \%$ and $1004 \mathrm{Md}$, and the average water saturation is $64 \%$.

In volumetric calculations, the amount of reserves in the reservoir is estimated to 689.42 million barrels. The south eastern part of the reservoir holds higher volumes of oil.

The model gave a better understanding of the geology of the reservoir and can be used for future development decisions.

\section{References}

[1] Yuliandri, I., et al. (2014) Facies (Rocktype) Modeling using Inverse Static Model Process from Porosity Distribution, Case from Baturaja Formation.

[2] Wiki, P. (2016) Geostatistical Reservoir Modeling.

[3] Serintel (2005) Integrated Reservoir Modeling. http://www.oil-gasportal.com/reservoir-management/integrated-reservoir-modelin g/

[4] Bohling, G. (2005) Introduction to Geostatistics and Variogram Analysis. Kansas Geological Survey, Lawrence.

[5] Gringarten, E. and Deutsch, C.V. (1999) Methodology for Variogram Interpretation 
and Modeling for Improved Reservoir Characterization. SPE Annual Technical Conference and Exhibition, Houston, 3-6 October 1999, 13.

https://doi.org/10.2118/56654-MS

[6] Bahar, A., Ates, H., Kelkar, M. and Al-Deeb, M. (2001) Methodology to Incorporate Geological Knowledge in Variogram Modeling. SPE Asia Pacific Oil and Gas Conference and Exhibition, Jakarta, 17-19 April 2001, 8.

https://doi.org/10.2118/68704-MS

[7] Cressie, N. and Hawkins, D.M. (1980) Robust Estimation of the Variogram. Journal of the International Association for Mathematical Geology, 12, 115-125. https://doi.org/10.1007/BF01035243

[8] Caers, J. (2003) Data Integration using the Probability Perturbation.

[9] Seo, Y., Kim, S., Singh, V.P. and Asce, F. (2013) Assessment of Uncertainty in the Spatial Distribution of Rainfall using Geostochastic Simulation. Journal of Hydrologic Engineering, 19, 978-992.

[10] Wafiy711 (2013) River Deposition, Geography Lesson.

https://wafiy711.wordpress.com/category/river-deposition/ 